\title{
NISTIR $5680^{\circ}$
}

\section{Proficiency Tests for the NIST Airborne Asbestos Program - 1993}

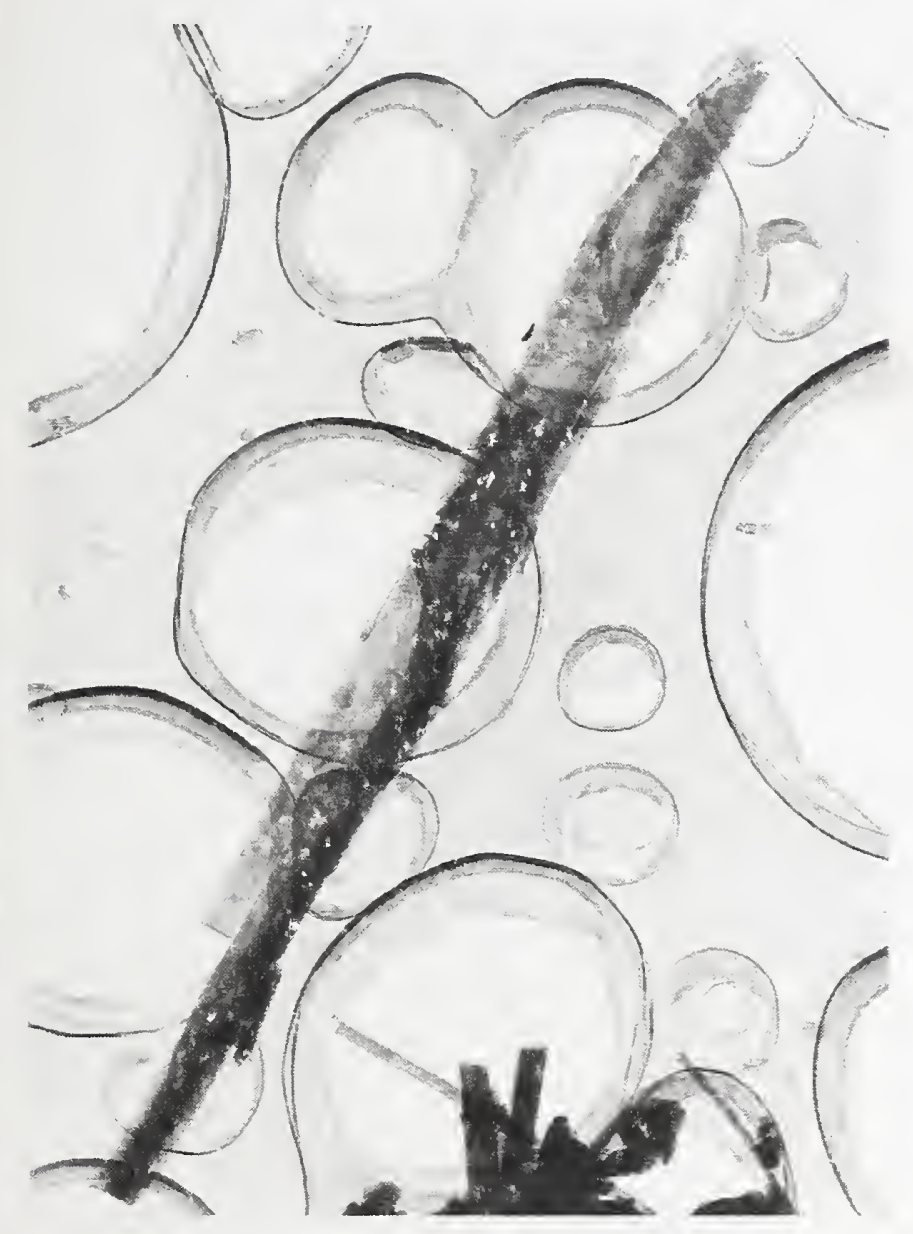

QC

100

.056

N0.5680

\section{Shirley Turner \\ Eric B. Steel \\ Owen S. Crankshaw* \\ Samuel Silberstein $\neq$ \\ Hazel M. Richmond}

U.S. DEPARTMENT OF COMMERCE

Technology Administration

National Institute of Standards

and Technology

Microanalysis Research Group

Surface and Microanalysis Science Division

Chemica! Science and Technology Laboratory

Gaithersburg, MD 20899

¥National Voluntary Accreditation Program

Gaithersburg, MD 20899

* Research Triangle Institute

Center for Environmental Measurements and Quality Assurance

Research Triangle Park, NC 27709-2194

June 1995

\section{5}





\title{
NISTIR 5680
}

\section{Proficiency Tests for the \\ NIST Airborne Asbestos \\ Program - 1993}

\section{Shirley Turner \\ Eric B. Steel \\ Owen S. Crankshaw* \\ Samuel Silberstein \\ Hazel M. Richmond F}

\author{
U.S. DEPARTMENT OF COMMERCE \\ Technology Administration \\ National Institute of Standards \\ and Technology \\ Microanalysis Research Group \\ Surface and Microanalysis Science Division \\ Chemical Science and Technology Laboratory \\ Gaithersburg, MD 20899
}

‡National Voluntary Accreditation Program

Gaithersburg, MD 20899

* Research Triangle Institute

Center for Environmental Measurements and Quality Assurance

Research Triangle Park, NC 27709-2194

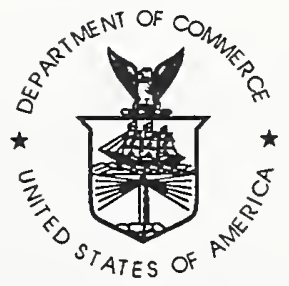

U.S. DEPARTMENT OF COMMERCE Ronald H. Brown, Secretary

TECHNOLOGY ADMINISTRATION

Mary L. Good, Under Secretary for Technology

NATIONAL INSTITUTE OF STANDARDS

AND TECHNOLOGY

Arati Prabhakar, Director 


\section{Preface}

The National Voluntary Laboratory Accreditation Program (NVLAP) of the National Institute of Standards and Technology (NIST), operates under Part 285 of Title 15 of the U.S. Code of Federal Regulations (CFR). NVLAP is an unbiased third party that accredits calibration and testing laboratories in response to mandates by the Federal Government through legislative or administrative action, requests from a government agency, or requests from private sector organizations.

NVLAP procedures and general requirements are documented in NIST Handbook $150^{\prime}$, NVLAP operates under a quality system documented in the National Voluntary Laboratory Accreditation Program Quality System ManuaR. NVLAP accreditation is based on evaluation of a laboratory's technical qualifications and competence for conducting specific test methods, measurements and services in specified fields of calibration or testing.

NVLAP accreditation for airborne asbestos analysis was established in response to the requirements set forth in Public Law 99-519, the Asbestos Hazard Emergency Response Act of 1986 (AHERA) $^{3}$. The specific requirements for the Airborne Asbestos Laboratory Accreditation Program (LAP), including the test method, are documented in the Program Handbook for Airborne Asbestos Analysis ${ }^{4}$. As part of the LAP, laboratories participate in proficiency testing twice a year to evaluate their ability to correctly analyze samples and to test the general knowledge of laboratory personnel. The results of the tests are sent to the participating laboratories in the form of a summary report.

NIST has published instructions and summary reports for proficiency tests conducted in the airborne asbestos program since $1990^{5 \cdot 7}$. The reports provide a historical record of proficiency testing materials sent to the laboratories so that they can be referenced in other publications and background material can be given to those laboratories entering the accreditation program. This report contains the instructions and summary reports issued for 1993 proficiency tests.

${ }^{1}$ J.L. Cigler, V.R. White, Editors, National Voluntary Laboratory Accreditation Program Procedures and General Requirements, NIST Handbook 150, March 1994.

${ }^{2}$ A.D. Tholen, National Voluntary Laboratory Accreditation Program Quality System Manual, NISTIR 5589, January 1995.

${ }^{3}$ Code of Federal Regulations, Asbestos-containing materials in schools; final rule and notice, 40 CFR Part 763, 41826-41905, 1987.

${ }^{4}$ E.B. Steel, S. Turner, H.W. Berger, NVLAP Program Handbook for Airborne Asbestos Analysis, National Institute of Standards and Technology, NISTIR 89-4137, August 1989.

${ }^{5}$ S. Turner, S.S. Doorn, E.B. Steel, J.M. Phelps, E.S. Windsor, K.K. Starner, Proficiency Tests for the NIST Airborne Asbestos Program - 1990, NISTIR 5431, May 1994.

${ }^{6}$ S. Turner, E.B. Steel, S.S. Doorn, S.B. Burris, Proficiency Tests for the NIST Airborne Asbestos Program - 1991, NISTIR 5432, May 1994.

${ }^{7}$ S. Turner, E.B. Steel, S.S. Doorn, S.B. Burris, Proficiency Tests for the NIST Airborne Asbestos Program - 1992, NISTIR 5433, May 1994. 


\section{Acknowledgements}

We thank Steven Burris and Tom Bergin for their assistance in preparing parts of PT93-1. 


\section{Table of Contents}

Chapter

Page

I. Instructions for PT93-1 . . . . . . . . . . . . . . . 1

II. Summary Report for PT93-1 . . . . . . . . . . . . . . . . . . . . . . 19

III. Instructions for PT93.2 . . . . . . . . . . . . . . . . . . 29

IV. Summary Report for PT93-2 f . . . . . . . . . . . . . 35 

I. Instructions for PT93-1

Page 1 of 38 
Part I - Identification of an Unknown

Instructions:

The objective of this portion of the 93-1 proficiency test is to identify an unknown mineral as either chrysotile, a regulated amphibole or "other". Please read the instructions carefully and examine the reporting form before beginning.

Note: For the purposes of this test, length and width should not be used to distinguish asbestos from nonasbestos.

1. The sample for this portion of the test is located in the enclosed grid box labelled: NIST 93-1 Unknown. For archival purposes, the laboratory may consider very carefully applying a light carbon coating onto the grid. Please try to avoid problem areas during the analysis. If the grid has been damaged during shipment, or is otherwise not conducive to analysis, please contact RTI.

2. Analyze several grains on the grid to determine the dominant mineral species (ignore minor or trace constituents).

3. Identify the dominant mineral species as either chrysotile, a regulated amphibole or as "other". Record identification and supporting evidence on Form 1.

4. After completing the analysis of this sample, please save the grid for use as an internal quality control sample.

5. Return Form 1 and supporting evidence to RTI for this part of the 93-1 proficiency test. 
NIST AIR PROGRAM PROFICIENCY TEST 93-1

Lab Code

\section{Part I - Identification of an Unknown}

Form 1

1. Put a check next to the identity of the dominant mineral species on the grid.

chrysotile (serpentine)

regulated amphibole (if checked, also check one of the following)

amosite (grunerite, cummingtonite)

crocidolite (riebeckite)

anthophyllite

actinolite-tremolite

other

2. In two pages or less, summarize the data used to make the determination. Criteria can include:

1) morphology, excluding aspect ratio

2) crystallographic data

3) chemical data

Include at least the minimum data needed to make the identification or if the "other" category was checked, include the minimum information necessary to distinguish the compound from the regulated minerals. 
Part II. Analysis of a set of filters

\section{General Discussion}

For this portion of the proficiency test, the laboratory has been sent thirteen filter quarters that simulate an AHERA set: five indoor filters, five outdoor filters, two field blanks and one sealed blank filter. The laboratory should use the AHERA method for preparation and analysis of the filters and should use the counting rules routinely applied in the laboratory for AHERA analyses with the exception that the AHERA stopping rules should not be applied. The laboratory should analyze the minimum number of filters necessary to determine the cleanliness of the filter set as defined by criteria in the AHERA method.

The grids analyzed from filters distributed in this proficiency test (PT 93-1) will be returned to RTI and subsequently be given to another lab for performance of a second analysis of selected grid squares (PT 93-2). Grid squares may then be further analyzed by RTI and/or NIST. Grid squares will therefore potentially be analyzed by two or more laboratories. It is necessary that each laboratory minimize contamination and beam damage. It is preferred that only one analysis of each grid square be performed; two analyses can be used for verification of, at most, $20 \%$ of the grid squares.

For this part of the proficiency test, the laboratory will be graded on correct implementation of the AHERA method. The laboratory will not be graded on the absolute value of the number of structures per grid square obtained. However, the sample sets from those laboratories reporting outlier values will be examined by NIST/RTI analysts. If a gross problem in counting, sample preparation, sample contamination, beam damage or sample handling is noted, a comment will be made on the individual laboratory's report sheet for this round, a note will be added to the NVLAP file for this laboratory, and the laboratory will be considered for an on site visit to evaluate the cause of the problem. For the next proficiency test (PT 93-2), the grids will be sent to other laboratories for reanalysis of selected grid squares and verified analyses will be performed. If laboratories obtain very different results from the same grid square, the cause will be investigated by NIST/RTI analysts and if a gross problem is noted, actions described above will be taken.

\section{Materials}

The materials provided for this portion of the proficiency test include:

- 13 filter quarters labelled as follows:

inside filters $\quad 11-15$

outside filters $\mathrm{O} 1-\mathrm{O} 5$

field blanks FB1, FB2

sealed blank $S B$

- A vial containing grids for sample preparation

- Three grid boxes labelled Grid Box 1, Grid Box 2, Grid Box 3 


\section{Preparation of filters}

The mixed-cellulose ester filter sections should be prepared as normally prepared in the laboratory (with ashing). The laboratory must use the 20 grids given in the last proficiency test (PT 92-2) and the 50 additional grids enclosed in the vial supplied for this proficiency test (if more grids are needed, contact RTI). As always, the laboratory should be careful to maintain the correct orientation (top vs. bottom) of the filters during preparation; the indentation of the cassette cowl on the filter quarter should be used as an indicator of orientation.

The laboratory must put the prepared grids into Grid Box 1, 2 or 3, exactly as specified below.

\begin{tabular}{|c|c|c|}
\hline Filter & Grid box & Grid slots \\
\hline I1 & 1 & $\mathrm{~A} 1, \mathrm{~A} 2$, etc. \\
\hline 12 & 1 & $\mathrm{~B} 1, \mathrm{~B} 2$, etc. \\
\hline 13 & 1 & $\mathrm{C} 1, \mathrm{C} 2$, etc. \\
\hline I4 & 1 & $\mathrm{D} 1, \mathrm{D} 2$, etc. \\
\hline I5 & 1 & $\mathrm{E} 1, \mathrm{E} 2$, etc. \\
\hline 01 & 2 & A6, A7, etc. \\
\hline $\mathrm{O} 2$ & 2 & B6, B7, etc. \\
\hline $\mathrm{O} 3$ & 2 & $\mathrm{C6}, \mathrm{C} 7$, etc. \\
\hline 04 & 2 & D6, D7, etc. \\
\hline O5 & 2 & E6, E7, etc. \\
\hline FB1 & 3 & $A 1, A 2$, etc. \\
\hline FB2 & 3 & $\mathrm{~B} 1, \mathrm{~B} 2$, etc. \\
\hline SB & 3 & $\mathrm{C} 1, \mathrm{C} 2$, etc. \\
\hline
\end{tabular}

\section{Determination of number of grid squares to be analyzed}

The information given on the top of Form 2 should be used to determine the minimum number of grid squares to be analyzed. The average grid square area given on Form 2 should be used throughout the remainder of the test (the laboratory need not measure grid square areas on these grids). 


\section{Analysis of filters}

\section{Labelling of grid squares}

The grids supplied by NIST/RTI are finder grids. These grids are indexed and therefore verified counting is possible. Figure 1 shows how the laboratory should record the grid squares which are analyzed.

\section{Orientation of grid}

The grids examined must be oriented as described in the instructions for Form 3 so verified counts may be performed in the next proficiency test. The laboratory should follow the instructions for Form 3 and complete the form. All grids should be oriented in the same manner.

\section{Examination of the grid squares for suitability}

Examine the grid squares for suitability using the following order (labelling scheme is described in Figure 1):

$$
\text { F1, E1, H1, D3, F10, E10, H10, B10, F12, E12, B12, B20, E20, F20, E3, F3, H3 }
$$

Choose grid squares for counting that satisfy the sample preparation criteria in the AHERA method. If more grid squares need to be selected, they may be randomly chosen from the grid.

\section{Analysis and recording instructions}

It is preferred that each grid square be analyzed only once for this proficiency test (more than one person can perform the analyses). All analyses should be conducted so that beam damage and contamination are minimized.

A recording form (Form 4) along with instructions for its completion are provided. In addition to this form, the laboratory should complete the normal analysis forms used by the laboratory for AHERA analyses. These laboratory sheets should be attached to the Form 4 completed for each grid square.

Form 4 has a column so that labs can indicate if a structure is countable or not countable. The laboratory should record all particles containing noncountable asbestos if the asbestos is marginal in length (close to but under 0.5 micrometers in length) or marginal in aspect ratio (close to but under $5: 1$ in length:width ratio), or if it is possible that analysts from other laboratories might consider the particle countable.

Verified analyses can be performed to obtain spot checks of, at most, $20 \%$ of the analyses. Verified counting should not be performed if the second count will significantly degrade the visibility or countability of structures. If grid squares are verified, the counts should be combined onto one recording form (Form 4). No more than two analyses should be performed on a grid square. 
NIST AIR PROGRAM PROFICIENCY TEST 93-1

Number of filters to analyze

The laboratory should analyze the minimum number of filters necessary to determine cleanliness by the AHERA method.

Form 5 is a summary sheet for reporting the filters analyzed and the total counts obtained for each grid square. Totals must be reported for the total number of occurrences (discussed in the instructions for Form 4), the total number of structures, the number of structures per $\mathrm{mm}^{2}$, and the number of structures per cc. Use additional sheets if necessary.

\section{Determination of cleanliness of a filter set}

On Form 6, the laboratory should summarize the results and work done to determine whether the filter set passes or fails the criteria given in the AHERA method for cleanliness.

\section{Materials to be returned to RTI}

The following materials must be returned to RTI for this portion of the test:

- All analyzed grids in Grid Boxes 1, 2, 3 (the laboratory can keep other prepared grids)

- Form 2

- Form 3

- Form 4 (for each grid square analyzed)

- The recording sheet used by the laboratory for AHERA analyses (completed and attached to Form 4 for each grid square analyzed)

- Form 5

- Form 6 


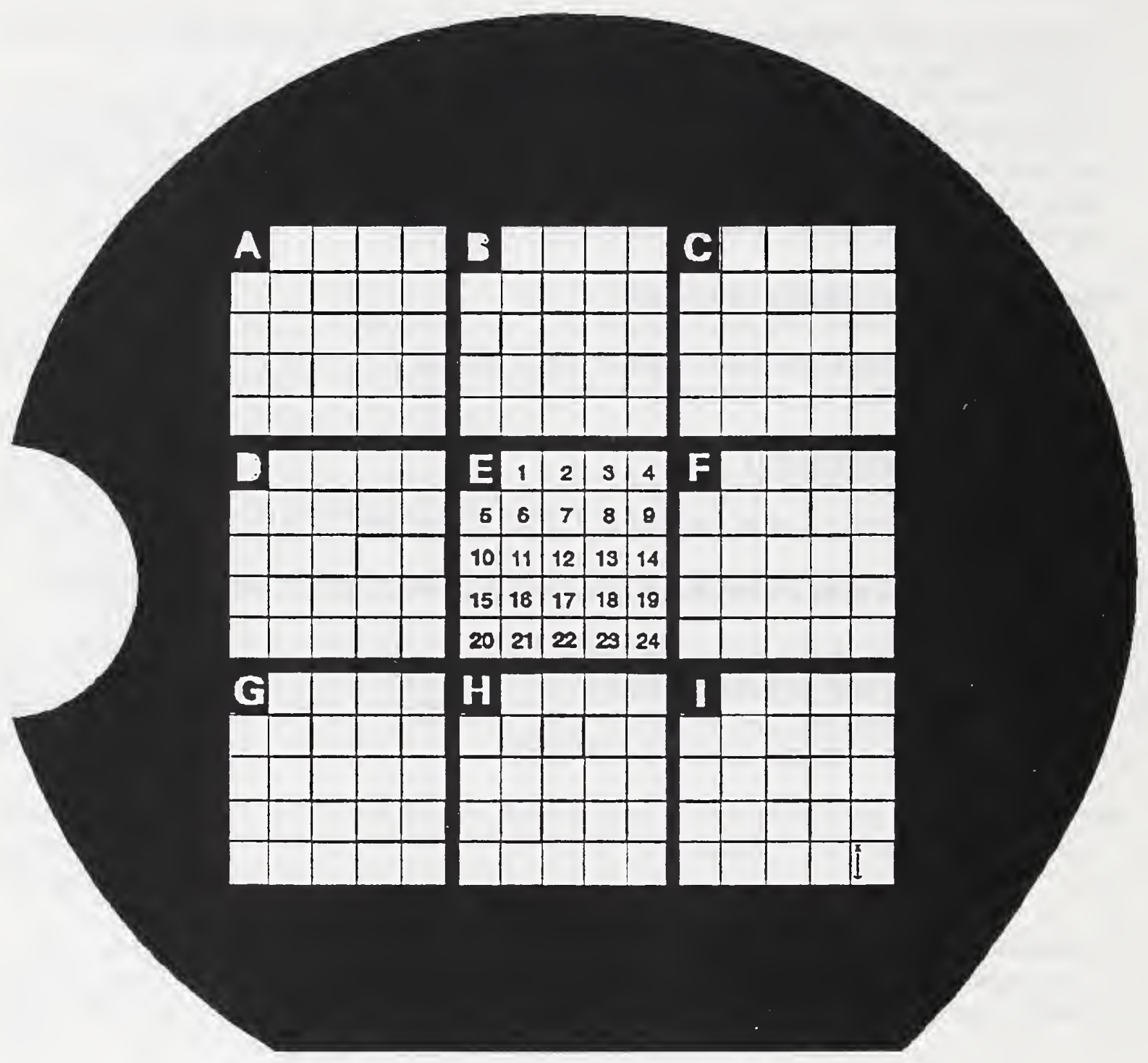

Figure 1. Indexed electron microscope grid. Grid squares in block " $E^{n}$ show the numbering system for this proficiency test. Use the same numbering scheme for each lettered region of grid squares. Grid square I-24 shows an example of an initial start point and scan direction for structure counting. 
NIST AIR PROGRAM PROFICIENCY TEST 93-1

Lab Code:

Form 2. Determination of the minimum number of grid squares to be counted

Parameters to be used in determination:

Filter diameter: $25 \mathrm{~mm}$

Volume of air collected by inside filters: 1800 liters

Volume of air collected by outside filters: 1450 liters

Average area of grid squares: $0.00931 \mathrm{~mm}^{2}$

Determine the minimum number of grid squares to be analyzed per filter (assuming it is necessary to analyze the inside, outside and blank filters):

Minimum number of grid squares per inside filter:

Minimum number of grid squares per outside filter:

Minimum number of grid squares per blank filter:

Show work or describe method used to determine the values given above (attach more pages if necessary): 


\section{Instructions for Form 3}

The following procedure is designed to ensure all laboratories count their grid squares in the same orientation and scan direction to allow for verified analyses in the next round of proficiency testing.

1. Place a grid into the TEM specimen holder. Insert the specimen holder into the TEM and illuminate the specimen. Find a particle on the grid replica. Increase the magnification to that which is typically used for asbestos analysis by your lab, keeping the particle in the field of view. Make sure the fluorescent screen is lowered. Move the particle using only one stage translation knob. Note the direction in which the particle moves. Record the particle's direction of movement (with a line) on Form 3. Move the particle again, using the other stage translation knob, and sketch that direction of movement relative to the first. This should roughly form a cross, which may not be square with the edges of the paper. The cross represents the translation directions of your microscope at the magnification used for asbestos analysis. Draw a letter " $F$ " onto the cross so the sides of the letter are parallel to the translation directions and the letter is upright and is not inverted. See example on Form 3.

2. Decrease the magnification and locate the letter " $F$ " on the finder grid. Increase the magnification of the TEM to that typically used for asbestos analysis by your lab, keeping the letter $F$ in the field of view. Compare the orientation of the " $F^{n}$ to the cross drawn in step 1 . If the letter $F$ is not oriented as shown in your sketch, remove the specimen holder and rotate or invert the grid as necessary to correctly align the grid. This may require several iterations to correctly align the grid.

3. When the correct orientation is found, record the grid's position in the specimen holder as shown in the example of the second part of Form 3. Indicate in your drawing where the straight side and the notched portion of the grid are located. All grids analyzed in this proficiency test should be oriented in the same manner (al ways check that the letter $\mathrm{F}$ is in the correct orientation and that the $\mathrm{X}-\mathrm{Y}$ translation directions allow translation roughly parallel to the grid bars).

4. The starting point of the traverse for structure counting must correspond to the upper left corner on the grid square. The " $\mathrm{X}$ " marks the starting corner of the traverse (your grid square may be at an angle to that shown in the example):

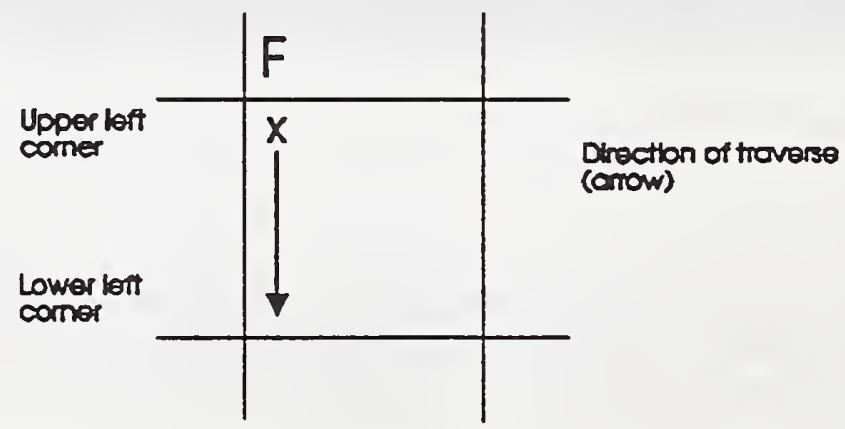

The initial direction of traverse must be from the upper left corner to the lower left corner of the grid square. 


\section{NIST AIR PROGRAM PROFICIENCY TEST 93-1}

5. Correct grid orientation can be checked by scanning a grid square from the upper left to lower left corner. If correctly oriented, the edge of the grid bar will remain in the field of view during the entire scan. Some allowance must be made for curvature or irregularly shaped grid bars. If the grid is not oriented properly, repeat steps 2 through 4 above. 
Lab Code:

Form 3. Grid Orientation

1. Sketch the orientation of the $X-Y$ translation directions of the electron microscope as projected onto the electron microscope stage. Record the letter " $\mathrm{F}^{n}$ as shown in the example below:

\section{EXAMPLE:}

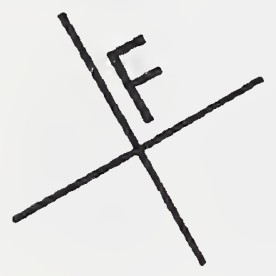

2. Sketch below the orientation of the grid relative to the sample holder as shown in the example below:

\section{EXAMPLE:}

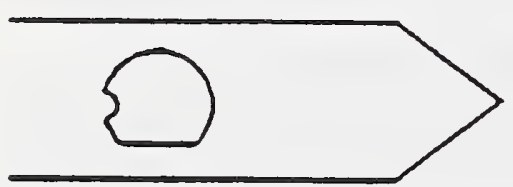




\section{NIST AIR PROGRAM PROFICIENCY TEST 93-1}

\section{Instructions for Form 4}

Structure counting should be done so as to minimize damage to asbestos containing structures. This can be accomplished by using a minimal beam intensity to sketch, measure and identify asbestos containing structures. In STEM mode or for EDXA, a small spot size should be used.

The laboratory should record all countable asbestos structures by using the AHERA counting rules as applied in the laboratory for routine analyses. The lab should record all particles containing noncountable asbestos if the noncountable asbestos is marginal in length (close to but under 0.5 micrometers in length) or marginal in aspect ratio (close to but less than 5:1 in length:width), or if it is possible that analysts from other laboratories might consider the particle countable. All fiber size data should be obtained at $0^{\circ}$ tilt of the electron microscope stage.

Note: For this proficiency test, the AHERA stopping rules should not be applied.

Instructions to complete Form 4 are as follows:

1. Refer to the attached example of Form 4.

2. Record information on the form heading as follows:

Record the information requested at the top of Form 4 for each recording sheet used. Information requested includes the filter identification (label on filter holders), grid box (1, 2 or 3), grid slot, grid square, date, NVLAP lab code, single or verified analysis (circle the type of analysis), the initials of the analyst(s) and the page number. At the completion of the grid square analysis, the totals for the number of countable structures and the number of occurrences (defined below) should be recorded on the first page. Only one form with as many pages as necessary should be submitted for each grid square (results of verified analyses should be combined onto one Form 4).

3. Record the following information under each column heading:

Length, width: Record size measurement in micrometers. The dimensions to be recorded are for structures identified as one countable unit. For instance, if a bundle is identified as a countable structure, the dimensions of the bundle are to be recorded (not the dimensions of an individual fiber within the bundle). If a cluster is identified as one countable structure, the dimensions of the cluster are to be recorded. More complicated cases are discussed in the sketch section.

Sketch: Sketch structures in a fairly detailed manner so they can be relocated or distinguished from other structures. If the structure intersects a grid bar, sketch the orientation of the grid bar relative to the structure. Sketch any other prominent features in the field of view along with the fiber(s) of interest. Be sure to draw the picture with the screen down and to draw the structure in its correct orientation. Also, make sure that the electron microscope stage is at $0^{\circ}$ tilt. 


\section{NIST AIR PROGRAM PROFICIENCY TEST 93-1}

If there are complicated arrangements of countable structures (corresponding to two or more countable structures):

- Sketch the structures in one box of the form.

- Label the countable fibers, bundles, clusters or matrices (i.e., F1, F2, F3 for fibers one, two and three, or B1, B2, B3, for bundles one, two and three, etc.). See example of Form 4 attached.

- Define structure dimensions and other information requested on subsequent lines of the form after putting the label in the sketch box.

Follow this procedure only if there are two or more countable asbestos structures in an arrangement. If the number of intersections is greater than or equal to three and therefore leads to a designation as a cluster ( 1 structure) do not label fibers or bundles and do not record information on subsequent lines of the form.

Verification: Leave this column blank. It will be used in the next proficiency test (PT 93-2).

\# Countable Structures: Record the number of countable asbestos structures using the AHERA counting rules as routinely applied in the laboratory for AHERA analyses. Record 0 structures if the structures are not asbestos or if the structures do not meet criteria defined in AHERA for countable asbestos structures.

\# Occurrences: An occurrence is a particle that contains countable asbestos. A particle may contain one, two or three countable asbestos structures (using AHERA rules) but will count as one occurrence. An example is given on the following page: sketch $\# 2$ has three countable structures but only one occurrence. The data on occurrences is being collected to aid in the comparison of analyses acquired by different laboratories.

Identification: An identification should be given either of the type of asbestos or as "other". The following abbreviations should be used:

$\begin{array}{ll}\mathrm{Ch} & \text { Chrysotile } \\ \mathrm{Am} & \text { Amosite } \\ \mathrm{Cr} & \text { Crocidolite } \\ \mathrm{Tr} & \text { Tremolite } \\ \mathrm{Ac} & \text { Actinolite } \\ \mathrm{Tr}-\mathrm{Ac} & \text { Tremolite-Actinolite } \\ \mathrm{An} & \text { Anthophyllite } \\ \mathrm{Ot} & \text { Other }\end{array}$

Note: In addition to completing Form 4 for each grid square, the laboratory should complete and attach the recording sheet normally used by the laboratory for AHERA analyses. 
Form 4. Recording sheet

Fllter Iden.:

Grid box:

Grid slot:

Grid square:
Page _ of

Grand totals:

* Countable Struct.:

\# Occurrences:
Date:

Lab Code:

Single Verified

Analyst(s):

\begin{tabular}{|c|c|c|c|c|c|c|c|c|c|c|c|c|c|}
\hline 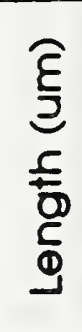 & $\begin{array}{l}\hat{E} \\
\text { है } \\
\frac{5}{0} \\
\frac{5}{3}\end{array}$ & Sketch & 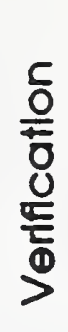 & 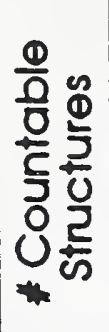 & 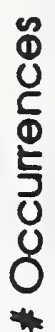 & 口 & $\begin{array}{l}\text { E } \\
\text { 己 } \\
\frac{5}{0} \\
\frac{5}{\Phi}\end{array}$ & $\begin{array}{l}\hat{\varepsilon} \\
\frac{f}{2} \\
\frac{5}{\xi}\end{array}$ & Sketch & 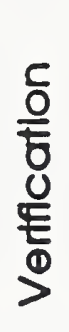 & 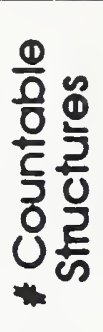 & 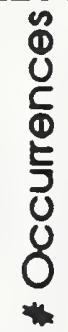 & $\varrho$ \\
\hline
\end{tabular}


Example of a completed Form 4.

Filter iden.: I3 Page 1 of 1

Grld box: $\frac{1}{1}$ Grand totals:

Grld slot: $\frac{C_{2}}{\text { Grld square: } F_{1}}$
\# Countable Struct.: 8

\# Occurrences: 5
Date: $\quad 3 / 15193$

Lab Code: 4111

Slngle Verified

Analyst(s): $A B C$

\begin{tabular}{|c|c|c|c|c|c|c|c|c|c|c|c|c|c|}
\hline 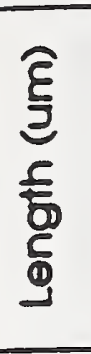 & $\frac{\hat{E}}{\frac{\hat{E}}{2}}$ & Sketch & $\begin{array}{l}\frac{c}{0} \\
\frac{0}{8} \\
0 \\
\frac{0}{0} \\
\text { D }\end{array}$ & 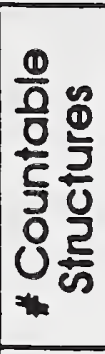 & 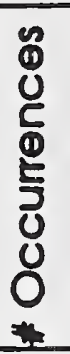 & 으 & 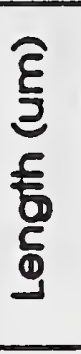 & $\begin{array}{l}\hat{E} \\
\frac{5}{2} \\
\frac{5}{3}\end{array}$ & Sketch & $\begin{array}{l}\frac{5}{0} \\
\frac{0}{6} \\
\frac{0}{0}\end{array}$ & 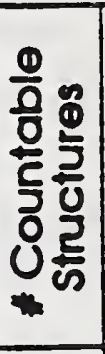 & $\begin{array}{l}0 \\
0 \\
0 \\
0 \\
5 \\
5 \\
0 \\
0 \\
0\end{array}$ & $\supseteq$ \\
\hline 1 & .2 & & & 1 & 1 & Tr & 3 & .1 & & & 1 & I & $C h$ \\
\hline & & & & & & & .4 & 1 & & & 0 & 0 & $C h$ \\
\hline 2 & .1 & $F$ & & 1 & & $\mathrm{Ch}$ & & & & & & & \\
\hline 1 & .1 & & & 1 & & $C h$ & & & & & & & \\
\hline 1 & .2 & $B$ & & 1 & & $C h$ & & & & & & & \\
\hline 3.7 & 1.3 & & & 1 & 1 & Ch & & & & & & & \\
\hline & & $F$ & & & & & & & & & & & \\
\hline 2 & .1 & Fl & & 1 & & $C h$ & & & & & & & \\
\hline 1 & .1 & 62 & & 1 & & $C h$ & & & & & & & \\
\hline
\end{tabular}

Totals: 74 
NIST AIR PROGRAM PROFICIENCY TEST 93-1

Lab Code:

Form 5. Summary sheet for counts

\begin{tabular}{|c|c|c|c|c|c|c|c|}
\hline Filter & $\begin{array}{r}\text { Grid } \\
\text { Box }\end{array}$ & $\begin{array}{c}\text { Grid } \\
\text { Slot }\end{array}$ & $\begin{array}{l}\text { Grid } \\
\text { Square }\end{array}$ & $\begin{array}{l}\text { Number of } \\
\text { Occurrences }\end{array}$ & $\begin{array}{c}\text { Number of } \\
\text { Countable } \\
\text { Structures } \\
\text { (AHERA) }\end{array}$ & $\begin{array}{c}\text { Number of } \\
\text { Structures/ } \\
\mathrm{mm}^{2}\end{array}$ & $\begin{array}{c}\text { Number of } \\
\text { Structures/ } \\
\text { cc }\end{array}$ \\
\hline & & & & & & & \\
\hline & & & & & & & \\
\hline & & & & & & & \\
\hline & & & & & & & \\
\hline & & & & & & & \\
\hline & & & & & & & \\
\hline & & & & & & & \\
\hline & & & & & & & \\
\hline & & & & & & & \\
\hline & & & & & & & \\
\hline & & & & & & & \\
\hline & & & & & & & \\
\hline & & & & & & & \\
\hline & & & & & & & \\
\hline & & & & & & & \\
\hline & & & & & & & \\
\hline & & & & & & & \\
\hline & & & & & & & \\
\hline & & & & & & & \\
\hline & & & & & & & \\
\hline & & & & & & & \\
\hline & & & & & & & \\
\hline
\end{tabular}


NIST AIR PROGRAM PROFICIENCY TEST 93-1

Lab Code:

Form 6. Determination of cleanliness of the filter set

Does the filter set pass or fail criteria for cleanliness given in the AHERA method?

How many filters were analyzed to reach this determination?

If the $\mathrm{Z}$-test was applied, what value for $\mathrm{Z}$ was determined?

Note: The EPA has issued clarifications for the application of the Z-test ${ }^{1}$. The EPA has recommended that 0.0025 structures/cc be substituted for concentrations of 0.0 structures/cc.

Describe below the logic used to determine the cleanliness of the site (attach more sheets, if necessary). In addition, if the Z-test was applied, show the work done to calculated the value for $Z$.

'EPA 560/5-89-001 (1989) Guidelines for Conducting the AHERA TEM Clearance Test to Determine Completion of an Asbestos Abatement Project, U.S. Environmental Protection Agency, Washington DC 20460. 
II. Summary Report for PT93-1 


\section{INTRODUCTION}

The National Voluntary Laboratory Accreditation Program (NVLAP) TEM Proficiency Test 93-1 was given to laboratories enrolled in the NVLAP Airborne Asbestos Fiber Analysis Program. The purpose of the test was to demonstrate how well NVLAP laboratories implement the AHERA procedure for analyzing a clearance set.

This report is a summary and explanation of the results of the test. Individual laboratory results are given on a separate scoring sheet enclosed with this report. All of the laboratories' results on each part of the proficiency test are summarized in Table 1.

\section{PART I. ANALYSIS OF UNKNOWN}

\section{Summary of test design}

The laboratories were asked to analyze several particles of an unknown material deposited on a grid, to identify the dominant species as chrysotile, regulated amphibole by type, or "other," and to document the identification.

\section{Identity of unkowown}

The material deposited on the grid was riebeckite (crocidolite) from the National Institute of Standards and Technology (NIST) Standard Reference Material (SRM) 1866.

Results submitted by laboratories

As shown in Table 1, 80 of 88 laboratories submitting results correctly identified the unknown material as crocidolite; two laboratories incorrectly identified the unknown as Amosite, and six incorrectly identified it as "other."

\section{PART II. ANALYSIS OF A SET OF FILTERS}

\section{Summary of test design}

Laboratories were sent 13 filter quarters representing an Asbestos Hazard Emergency Response Act (AHERA) ${ }^{1}$ clearance set. They were labelled I1-I5, O1-O5, FB1-FB2 and SB, designating indoor, outdoor, field blank, and sealed blank filters, respectively. Laboratories were also sent finder grids and instructions or preparing the filters, orienting the grids in the TEM, and recording the results of analysis of the filters. The laboratories were asked to prepare and anaiyze the filters by the AHERA method, but to disregard the AHERA stopping rules for counting structures. Laboratories were instructed to determine whether the clearance set passed or failed the cleanliness criteria given by AHERA, and to return the prepared grids to Research Triangle Instirute (RTI).

'Code of Federal Regulations, Asbestos-containing materials in schools: final rule and notice, 40 CFR Part 763, 41826-41905, 1987. 


\section{Materials deposited onto filters}

The background component on the inside and outside filters is St. Louis Urban Dust (SLUD), NIST SRM 1648. Chrysotile was deposited in two distinct loadings: filters I1, 13, 15, O2 and O4 were less heavily loaded than filters 12 and 14.

\section{Results submitted by laboratories}

Laboratories were evaluated on a variety of categories, including: 1) calculation of the number of grid squares to be analyzed, structures $/ \mathrm{mm}^{2}$, structures $/ \mathrm{cm}^{3}$, and the Z-value; 2) sample measurement and quality assurance; and 3) additional categories shown in Table 1. Additionally, as discussed below, each laboratory's counts were compared to those from other laboratories that analyzed the same filter.

\section{CAlCUlations}

\section{Number of grid squares}

The laboratories were required to calculate the number of grid squares to be analyzed for the inside and outside filters, using the volume of air sampled (1450 and $1800 \mathrm{~L}$ ) and the average grid square area $\left(0.00931 \mathrm{~mm}^{2}\right)$ given in the instructions.

Table 1 shows that most of the laboratories calculated 7 or 10 grid squares for blank filters. The AHERA ${ }^{1}$ method is ambiguous; one section specifies that 10 grid squares should be analyzed for blark filters; another section specifies a minimum area of $0.057 \mathrm{~mm}^{2}$. Seven grid squares of area $0.00931 \mathrm{~mm}^{2}$ will give an area greater than $0.057 \mathrm{~mm}^{2}$. Some laboratories calculated the number of grid squares using the area, but then incorrectly rounded down to 6 grid squares. For this test, either 7 or 10 grid squares is considered correct, as shown in Table 1. Laboratories will be instructed to use 10 grid squares in future NVLAP proficiency tests.

\section{Structures $/ \mathrm{mm}^{2}$ and structures $/ \mathrm{cm}^{3}$}

Laboratories were required to repor the loading density of asbestos structures on the filters in units of structures $/ \mathrm{mm}^{2}$, and the airborne concentration of asbestos structures in units of structures/cm ${ }^{3}$. NVLAP calculated expected loading densities from the countable structures reported by the laboratories, and airborne concentrations using the laboratories' reported structures/mm ${ }^{2}$. The calculated values for structures $/ \mathrm{mm}^{2}$ and structures $/ \mathrm{cm}^{3}$ were then compared to the reported values. Errors were identified and error points were assigned as described in the attached Explanation of NVLAP TEM Proficiency Test 93-1 Scoring Sheet.

Some laboratories reported the loading density per grid square rather than per filter. These grid square values were averaged by NVLAP to determine the loading density per filter. Other errors made by the laboratories in calculating structures $/ \mathrm{mm}^{2}$ include averaging structure counts by dividing by the wrong number of grid squares, using an incorrect grid square area, using number of occurrences instead of number of countable structures, and arithmetic errors. Errors made by the laboratories in calculating structures $/ \mathrm{cm}^{3}$ include arithmetic and rounding errors. 
It is strongly recommended that a computer or calculator be programmed to calculate final results (structures $/ \mathrm{cm}^{3}$ or Z-value) directly from structure counts to minimize errors resulting from rounding intermediate results or logarithms. At the least, it is recommended that laboratories report structures/mm to the nearest whole number, which all laboratories did in the present test, and structures/cm ${ }^{3}$ to 4 decimal places. It is further recommended that logarithms used for the Z-test contain at least 4 decimal places. Laboratories are referred to an EPA document ${ }^{2}$ for guidance and worked examples. Structures $/ \mathrm{mm}^{2}$ are reported to I decimal place on the scoring sheets because most laboratories reported them to at least 1 decimal place.

Another common mistake is that some laboratories reported the detection limit or " $<$ " the detection limit for structures $/ \mathrm{mm}^{2}$ or structures $/ \mathrm{cm}^{3}$ when no structures were detected on a filter. In the future, laboratories should report 0 structures $/ \mathrm{mm}^{2}$ and 0 structures $/ \mathrm{cm}^{3}$ for 0 structures. In this proficiency test, the tolerances were large enough so that errors were not assigned for this mistake, but tolerances may be smaller in future tests. We have commented on the failure to report 0 structures/mm and 0 structures $/ \mathrm{cm}^{3}$ for 0 structures only on the scoring sheets of laboratories that reported $>9 \mathrm{structures} / \mathrm{mm}^{2}$ and $>0.0025$ structures $/ \mathrm{cm}^{3}$. The reason for this is that 0 structures $/ \mathrm{mm}^{2}$ is replaced by 0.0025 structures $/ \mathrm{cm}^{3}$ for the Z-value calculation. Thus, reporting 9 instead of 0 structures $/ \mathrm{mm}^{2}$, or 0.0025 instead of 0 strucrures $/ \mathrm{cm}^{3}$, does not introduce any errors inso the Z-value calculation.

Generally, laboratories whose reported results were inconsistent with expected values should determine the cause and correct the problem.

\section{Zvalue}

Laboratories were required to report a value for $Z$ if the $Z$-test was used. $Z$ values were calculated by NVLAP using the reported airbome concentrations. Table 1 shows that one fourth of the laboratories calculated $Z$ incorrectly.

Errors made by the laboratories include using structures $/ \mathrm{mm}^{2}$ instead of structures $/ \mathrm{cm}^{3}$, using an incorrect formula, using base-10 rather than nanural logarithms, not analyzing all of the filters required to perform the test, incorrectly transcribing data from the worksheet to the answer sheet, and arithmetic errors.

The AHERA method' requires substitution of the calculated value for the detection limit (approximately 0.005 ) for 0 structures $/ \mathrm{cm}^{3}$ in calculating Z, but a subsequent EPA document ${ }^{2}$ recommends substitution of 0.0025 structures $/ \mathrm{cm}^{3}$. An error was assigned on the scoring sheet if the reported Z-value was not within $1 \%$ of the value calculated either way. However, the expected value shown on the scoring sheet was calculated using 0.0025 structures $/ \mathrm{cm}^{3}$ because approximately $90 \%$ of the laboratories calculared Z in this way. In future proficiency tests, NVLAP will instruct laboratories to substitute 0.0025 for 0 structures/cm ${ }^{3}$.

${ }^{2}$ U.S. Environmental Protection Agency, Office of Toxic Substances, Washington, D.C., Guidelines for Conducting the AHERA TEM Clearance Test to Determine Completion of an Asbestos Abatement Project, EPA 560/5-89-001, May, 1989. 
NVLAP TEM Proficiency Test 93-1

\section{Z-test interpretation}

As shown in Table 1, each laboratory reported correctly that the filter set failed the AHERA' criterion for cleanliness $(Z>1.65)$.

\section{SAMPLE MEASUREMENT AND QUALITY ASSURANCE}

Laboratories were evaluated on various aspects of their implementation of the AHERA ${ }^{l}$ method. Laboratories were required to analyze at a minimum the number of grid squares calculated for analysis, at least two grids per filter, and all 13 filters from the sample set.

Table 1 shows that all laboratories obtained an asbestos structure loading on field and sealed blank filters smaller than required by AHERA'.

The loading of chrysotile on the inside and outside filters was examined to determine if filters or grids were switched. Laboratories reporting grids from filters I1-15, O2, and O4 for which 2 or more grid squares had 0 counts were recognized as having a measurement or quality assurance problem. Conversely, filters $\mathrm{O1}, \mathrm{O} 3$ and 05 , which had been loaded only with SLUD, were examined for high loadings of chrysotile. If a loading of 3 or more structures/grid square occurred, at least one analysis form submitted by the laboratory for the grid was examined to determine the size and complexity of the asbestos structures. If the number of structures, and the size and complexity of the structures indicated that the chrysotile was not from the SLUD sample, the laboratory is suspected of having a measurement or quality assurance problem. We concluded that four laboratories switched either grids or filters, as evidenced by both types of error.

\section{ADDITIONAL ERRORS AND COMMENTS}

\section{Determination of the number of occurrences}

The laboratories were instructed to determine the number of occurrences of particles containing countable asbestos, and to report this number on the summary sheet for counts. The number of occurrences was compared by NVLAP to the number of countable asbestos structures to determine two types of error: 1) the number of occurrences greater than the number of countable structures; and 2) zero occurrences reported with a positive number of countable strucrures. Either of these errors indicates a misunderstanding of the definition of occurrences.

\section{Ranking}

The number of countable structures for each of filters I1-15, O2, and 04 were compared to those of other laboratories that measured the same filter. Up to four laboratories measured any one filter. Seven laboratories consistently obtained low counts for the 7 filters, and one laboratory obtained consistently high counts. Comments were made on these laboratories' scoring sheets. These laboratories are advised to determine the cause of the high or low ranking by examining sample preparation, analysis procedures, and counting protocols. NVLAP did not penalize laboratories for biased structure counts in this proficiency test. 
NUMBER OF LABORATORIES PARTICIPATING IN PROFICIENCY TEST NUABER OF LABORATORIES PASSING PROFICIENCY TEST

76

NO. OF ERROR

POWTS

Part I. IDENTIFICATION OF UNKNOWN

0.00

1.25

2.50

NO. OF ERRORS

\begin{abstract}
Pan II. ANALYSIS OF A SET OF FILTERS
1. CALCULATIONS
\end{abstract}

Gnd square calculetions

Structures/mms and structuresicm calculations

$Z$ calculation

Z-teat interprotution: peas or tal

2. SAMPLE MEASUREMENT AND OUAUTY ASSURANCE

Averege of blento. stuctureedmm

Meximum of blentes strcturea/mm

Number of nesces finers anayed

Number of ousedic fiters ancired

Number of fiold blenk fillers anthzes

Number of seaved btant filten anaryed

Number of filters wath $<2$ gndastiter

Number of filters whe reponed < caleuteted and squeres

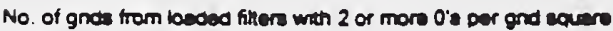

No. of gndis from bienk outude filters $(01.03 .05)$ whe 3 or mors etrecturealortd eq

No. of gnd soueres with 0 cocurrences and poutw no. of countable gructures

NO. OF ERRORS

NO. OF LABS

NO. OF LABS

WITH ERRORS

22

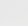

RS O. OF LABS

\title{
80
}

2

BS

0

1

73

12

0

60

12

7

3

1

1

S

0




\section{Additional comments}

Where appropriate, NVLAP made comments on individual scoring sheets about additional aspects of a laboratory's test resuits. 
Your laboratory's results are shown in the REPORTED column of the NVLAP scoring sheet. The results were compared to the values in the EXPECTED column. ERRORS resulted when reported values deviated from expected values as described below. Errors were grouped together and ERROR POINTS assigned, also as described below. Laboratories with fewer than 2.50 total error points passed the NVLAP TEM 93-1 proficiency testing round.

\section{Part I. IDENTIFICATION OF UNKNOWN}

\section{ERROR DESCRIPTION}

"Other" than regulated asbestos

Incorrect regulated amphibole

\section{ERROR POINTS}

2.50

1.25

\section{Part II. ANALYSIS OF A SET OF FILTERS}

\section{CALCULATIONS}

\section{Grid Square Calculations}

Any reported number of filters different from the expected number is an error. 0.5 error point was assigned for each error, with a maximum of 1 error point for 2 or more errors.

Structures $/ \mathrm{mm}^{2}$, Structures $/ \mathrm{cm}^{3}$, and Z Calculations

ITEM

Structures $/ \mathrm{mm}^{2}$ Calculated by NVLAP from countable structures reported by laboratory.

Structures $/ \mathrm{cm}^{3} \quad$ Calculated by NVLAP from structures $/ \mathrm{mm}^{2}$ reported by laboratory.

\section{EXPECTED VALUE}

\section{ERROR ASSIGNMENT}

An error results if the reported value is not within 18 structures $/ \mathrm{mm}^{2}$ of the expected value.

An error results if the laboratory value is not within 0.005 structures $/ \mathrm{cm}^{3}$ of the expected value.

The reported value is considered correct if it is within $1 \%$ of either expected value. An error is assigned 0.5 error point. 
The scoring system is designed to avoid counting errors twice, as illustrated by this example: A laboratory makes an error in calculating structures $/ \mathrm{cm}^{3}$ from structures $/ \mathrm{mm}^{2}$ for filter 12 , and makes no further errors in calculating Z. NVLAP assigns an error for the filter 12 structures $/ \mathrm{cm}^{3}$ calculation, but not for the $Z$ calculation even though $Z$ is not correct. The ERROR-FREE CALCULATION column of the scoring sheet contains values calculated by NVLAP from the reported structure counts, but is not used in scoring. The values in this column agree with the expected value if the laboratory made no errors at any stage of the calculations.

Errors were assigned only for structures $/ \mathrm{mm}^{2}$ or structures $/ \mathrm{cm}^{3}$ calculations for filters that were measured; failure to measure enough filters is penalized elsewhere in the scoring sheet.

\section{Z Interpretation}

A Z interpretation error was assigned 1 error point.

2. SAMPLE MEASUREMENT AND QUALITY ASSURANCE

\section{ITEM}

Average of blanks, structures $/ \mathrm{mm}^{2}$

Maximum of blanks, structures $/ \mathrm{mm}^{2}$

Number of inside filters analyzed

Number of outside filters analyzed

Number of field blank filters analyzed

Number of sealed blank filters analyzed

Number of filters with reported $<$ calculated grid squares

Number of filters with $<2$ grids/filter
NUMBER OF ERRORS

1 if average $\geq$ expected value 1

1 if maximum > expected value

Excess of expected number over laboratory number

Excess of expected number over laboratory number

Excess of expected number over laboratory number

Excess of expected number over laboratory number

Number

Number
ERROR POINTS 1

1

0.5 per error

0.5 per error

1 per error

2 per error

0.5 for 1 error; 1.0 for $\geq 2$ errors

0.5 for 1 error; 1.0 for $\geq 2$ errors 
Combined score for following 2 irems:

Number of grids from loaded filters with 2 or more 0's per grid square

Number of grids from blank outside filters $(01,03,05)$

with 3 or more strucrures/grid square

NOTE: Errors in both of the last two items suggest a filter switch.

\section{ADDITIONAL ERRORS}

No error points were assigned for the following additional errors:

Number of grid squares with 0 occurrences and positive number of countable structures Number of grid squares with (number of occurrences) > (number of countable structures)
Number

Number
Take the maximum of the number of errors for the following 2 items; assign 0.5 error point for 1 error; 1 error point for $\geq 2$ errors. 
III. Instructions for PT93-2

Page 29 of 38 
The first part of this proficiency test, Round 93-2, consists of identification of an unknown mineral.

\section{Instructions for Part I - Identification of an Unknown}

The objective of this portion of the 93-2 proficiency test is to identify an unknown mineral as either chrysotile, a regulated amphibole, or "other."

1. The sample for this portion of the test is located in the enclosed grid box labelled "93-2 Unknown." Inspect the grid immediately upon receipt to check for damage or other problems. If the grid is for any reason not suitable for analysis, contact Owen Crankshaw at 919-541-7470 immediately.

2. Analyze several particles on the grid to determine the dominant mineral species (ignore minor or trace constituents).

3. Identify the dominant mineral species as either chrysotile, a regulated amphibole, or as "other." Record identification on Form 1 and provide supporting data for identification.

4. After completing the analysis of the sample, save the grid for use as an internal quality control sample.

5. Return Form 1 and supporting data to RTI. 
NVLAP AIRBORNE ASBESTOS PROFICIENCY TEST 93-2

Form 1. Identification of an Unknown

LAB CODE

1. Put a check next to the identity of the dominant mineral species on the grid. chrysotile (serpentine) regulated amphibole (if checked, also check one of the following) amosite (grunerite, cummingtonite) crocidolite (riebeckite) anthophyllite actinolite-tremolite other

2. In two pages or less, summarize the data used to make the identification determination. Criteria can include:
1) morphology
2) crystallographic data
3) chemical data

Include at least the minimum data needed to make the identification, or if the "other" category. was checked, include the minimum information necessary to distinguish the mineral from the regulated minerals. 
The second part of proficiency test round 93-2 continues where Round 93-1 left off. Each main laboratory will receive three grids which were prepared by another laboratory participating in Round 93-1. The lab will inspect the grids for their ability to be analyzed (specific grid openings will be listed) and will then proceed to analyze one opening on each of the three grids. The data will be entered on the form previously used in Round 93-1. These data will be reported to RTI, and the analyzed grids will be retained by the laboratory. Following completion of Round 93-2, the laboratories will be sent materials for Round 94-1. Round 94-1 will include the count sheets from Round 93-1 which represent the original analysis of the grid openings being reanalyzed by your laboratory in Round 93-2. The laboratory will be asked to perform a verified count of the three grid openings using their data and the data of the original laboratory. The three grids which were retained from Round 93-2 will be used for verification of structure discrepancies. The laboratories will also be sent an unknown for identification in Round 94-1.

\section{Instructions for Part II - Verified Analysis}

1. The laboratory has been sent a grid box of grids prepared by another laboratory. Please exercise great care in handling this grid box. Be careful to avoid contamination and to avoid losing or damaging grids.

2. Upon arrival of samples in your laboratory, please examine the grids in the transmission electron microscope as soon as possible. This will allow RTI to send replacement grids if the grids received are deemed to be of inadequate quality.

3. Using the AHERA TEM test method, assess only the assigned grid squares listed on Form

2. An overall evaluation of the entire grid is not needed; just an assessment of the previously analyzed grid openings which are candidates for reanalysis by your laboratory. The goal of the evaluations is to find one grid square on each of the grids that is acceptable for analysis.

4. Assess the grid squares in the sequence given on Form 2. If a grid square is found to be acceptable for analysis, no more grid squares should be evaluated on that grid.

5. For each grid square evaluated, record on Form 2 next to the appropriate grid slot and grid square ID a $\mathbf{Y}$ (yes) or $\mathbf{N}$ (no) for each evaluation criterion and for the acceptability of the grid square. Add a comment if other features are noteworthy.

6. In the summary table at the bottom of Form 2, write the grid slot and the acceptable grid square for that grid. If no grid square was found to be acceptable, write "none" in the acceptable grid square column. 
NVLAP AIRBORNE ASBESTOS PROFICIENCY TEST 93-2

Part II Instructions - Page 2

7. Fill in your lab code at the top of Form 2 and mail the form to RTI in the enclosed stamped, addressed envelope. Telefaxes of Form 2 are acceptable and should be faxed to 919-541-7386 (note that faxes of other materials for Round 93-2 will not be acceptable). In order to expedite this round, it is essential that Form 2 is received by fax or mail at RTI by January 14, 1994.

8. Place the grids in the TEM in the same orientation as described in the instructions for Proficiency Test Round 93-1 (Form 3). It is critical that the correct orientation is obtained.

9. Analyze one grid square from each grid (the first grid square for each sample which was deemed satisfactory in steps 1-7 above) following the instructions given for Form 4 in Proficiency Test Round 93-1. Report the data using additional copies of. Form 4 (93-1). Use as many copies of Form 4 (93-1) as are necessary (additional copies are enclosed). The laboratory should not record data for analyses on their own laboratory count sheets.

10. Return a copy of the count sheets to RTI. Do not return the grids at this time.

Note: The instructions in items 8 and 9 refer to material given in Proficiency Test Round 93-1. If the necessary instructions or forms are not available, please contact Owen Crankshaw at RTI for assistance (telephone 919-541-7470). If your laboratory did not participate in Test Round 93-1, copies of necessary forms from that round have been included in this package. 
NVLAP AIRBORNE ASBESTOS PROFICIENCY TEST 93-2

Form 2. Grid Preparation Quality Assessment

LAB CODE

\begin{tabular}{|c|c|c|c|c|c|c|}
\hline $\begin{array}{c}\text { Grid } \\
\text { Slot }\end{array}$ & $\begin{array}{c}\text { Grid } \\
\text { Square }\end{array}$ & $\begin{array}{c}\leq \text { 5\% } \\
\text { Holes }\end{array}$ & $\begin{array}{c}\leq 25 \% \\
\text { Particulate } \\
\text { Matter }\end{array}$ & $\begin{array}{c}\text { Uniform } \\
\text { Particle } \\
\text { Loading }\end{array}$ & $\begin{array}{c}\text { Acceptable } \\
\text { for } \\
\text { Analysis }\end{array}$ & Comments \\
\hline A1 & & & & & & \\
\hline A1 & & & & & & \\
\hline A1 & & & & & & \\
\hline C1 & & & & & & \\
\hline C1 & & & & & & \\
\hline C1 & & & & & & \\
\hline E1 & & & & & & \\
\hline E1 & & & & & & \\
\hline E1 & & & & & & \\
\hline
\end{tabular}

\begin{tabular}{|c|c|}
\hline Grid Slot & Acceptable Grid Square D \\
\hline \hline $\mathbf{A 1}$ & \\
\hline C1 & \\
\hline E1 & \\
\hline
\end{tabular}


IV. Summary Report for PT93-2

Page 35 of 38 


\section{SUMMARY REPORT FOR NVLAP TEM PROFICIENCY TEST 93-2}

\section{INTRODUCTION}

The National Voluntary Laboratory Accreditation Program (NVLAP) transmission electron microscopy (TEM) Proficiency Test 93-2 was given to laboratories enrolled in the NVLAP Airborne Asbestos Fiber Analysis Program. One purpose of the test was to demonstrate the laboratories' abilities to identify an unknown mineral. The second part of the test was a reanalysis of grid openings which had previously been analyzed in test round 93-1.

\section{PART I. ANALYSIS OF AN UNKNOWN}

\section{Summary of test design}

The laboratories were asked to analyze several particles of an unknown mineral deposited on a copper TEM grid, and to identify the dominant mineral species as chrysotile, regulated amphibole by type, or "other."

\section{Identity of unknown}

The material deposited on the grid was purchased from Ward's Natural Science, Inc., and was labelled sepiolite from Turkey. The identification of sepiolite was confirmed by $\mathrm{x}$-ray diffraction (XRD) and TEM analyses. An x-ray diffraction pattern of the material is shown in Figure 1. The pattern is consistent with the presence of sepiolite and dolomite as the major phases as shown by the Joint Committee on Powder Diffraction Standards (JCPDS) reference intensities and peak positions given under the pattern. For comparison, the reference intensities and peak patterns for chrysotile and anthophyllite are also given in the figure. Evaluation by TEM and energy dispersive $x$-ray analysis (EDXA) showed that the major phase is fibrous and that it contains magnesium and silicon which is consistent with the presence of sepiolite.

\section{Results submitted by laboratories}

All 79 laboratories submitting results correctly identified the unknown sample as "other." Although further identification was not required, 32 laboratories correctly identified the unknown as sepiolite. Other laboratories suggested identities such as palygorskite, talc, serpentine, and trioctahedral smectite.

\section{PART II. REANALYSIS OF PREPARED SAMPLES}

\section{Summary of test design}

Laboratories were sent TEM grids which had been prepared and analyzed by another laboratory enrolled in the NVLAP program. Laboratories were asked to verify the quality of preparation of the grids and to analyze them. The laboratories were to analyze the same grid openings on the samples that the previous laboratory had analyzed. 
Results submitted by laboratories

All 79 laboratories participating in the test submitted reanalysis counting sheets to RTI. Twenty-three of the 237 grids received by laboratories participating in the test were reported to be of inadequate quality for analysis. A record of the laboratories' performance on sample preparation will be maintained over this and subsequent proficiency tests. One unacceptable grid preparation on this test is likely not significant. However, evaluations in subsequent tests may indicate that this is part of a pattern of inadequate sample preparation and that remedial action should be taken by the laboratory. If two or more grids have been judged as inadequately prepared in this proficiency test, the laboratory should review its sample preparation procedure. Laboratories which had at least one of their grids deemed unacceptable by the reanalysis have received a note to that effect on their individual report.

\section{RESULTS}

All 79 participating laboratories passed test TEM 93-2. No error points were assigned because each laboratory correctly identified the unknown sample, and submitted the required number of counting sheets. 

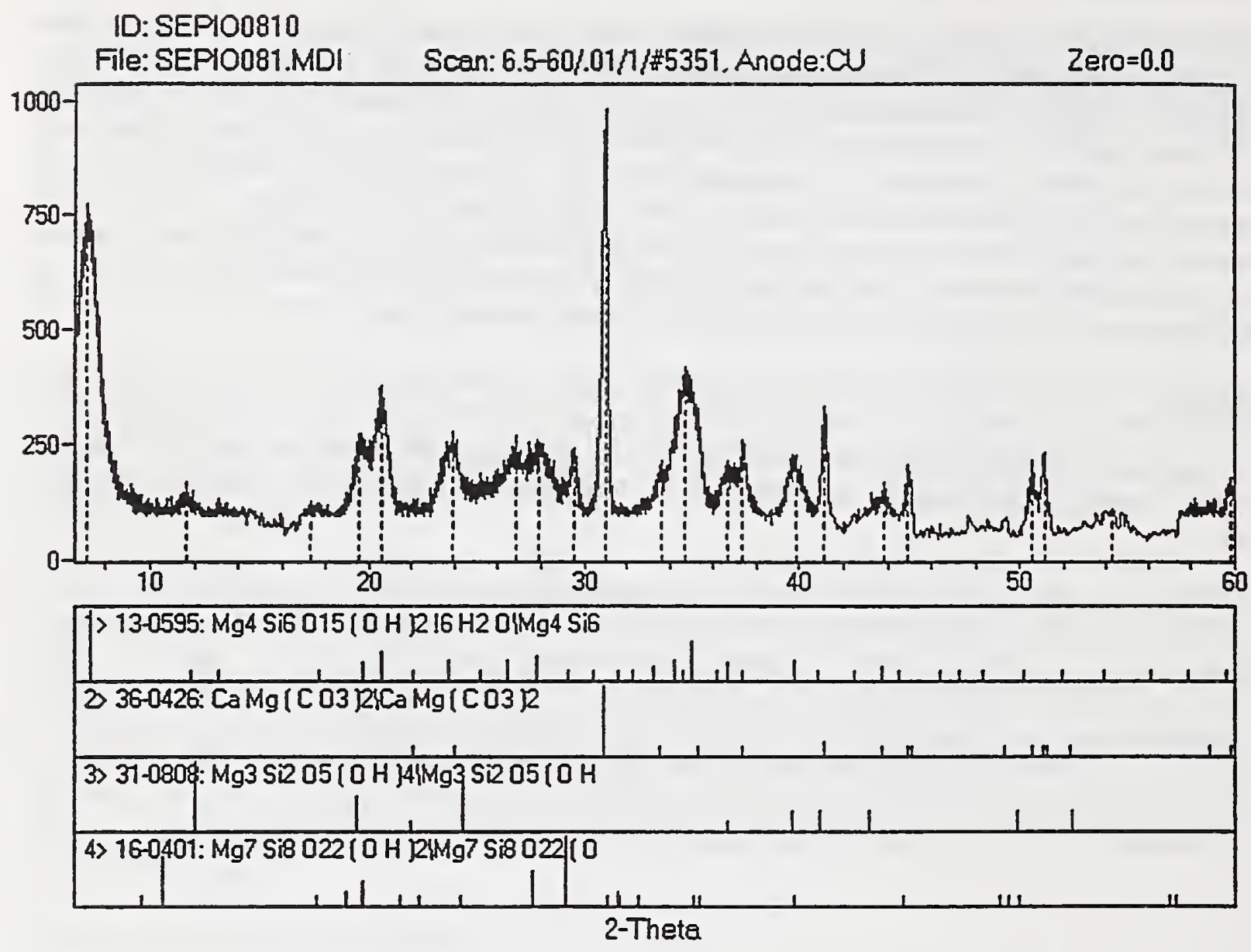

JCPDS $13-0595=$ SEPIOLITE, JCPDS $\$ 36-0426=$ DOLOMITE, JCPDS

\$31-0808=CHRYSOTIILE, JCPDS \$16-0401=ANTHOPEYTIITE

Figure 1. X-ray diffraction pattern for sepiolite and reference intensities and peak positions for sepiolite, dolomite, chrysotile, and anthophyllite. 

